\title{
Mechanically interlocked carbon nanotubes as a stable electrocatalytic platform for oxygen reduction
}

Dominik Wielend $^{[\mathrm{a}] \dagger}$, Mariano Vera-Hidalgo ${ }^{[\mathrm{b}] \dagger}$, Hathaichanok Seelajaroen $^{[\mathrm{a}]}$, Niyazi Serdar Sariciftci $^{[a]}$, Emilio M. Pérez*[b], Dong Ryeol Whang*[a, c]

[a] Linz Institute for Organic Solar Cells (LIOS), Institute of Physical Chemistry, Johannes Kepler University Linz, Altenberger Strasse 69, 4040 Linz, Austria.

[b] IMDEA Nanociencia, Ciudad Universitaria de Cantoblanco, c/Faraday 9, 28049 Madrid, Spain. [c] Department of Advanced Materials, Hannam University, 1646 Yuseong-Daro, Yuseong-Gu, Daejeon, 34054 Republic of Korea

$\left[{ }^{\dagger}\right]$ Dominik Wielend and Mariano Vera-Hidalgo contributed equally to this work.

(*Email: emilio.perez@imdea.org,whang@hnu.kr)

\section{Supporting information}

\section{Synthesis and characterization of 2,6-bis(oct-7-en-1-yloxy)anthracene-9,10-dione (C8-} AQ-C8):<smiles>O=C1c2ccc(O)cc2C(=O)c2ccc(O)cc21</smiles>

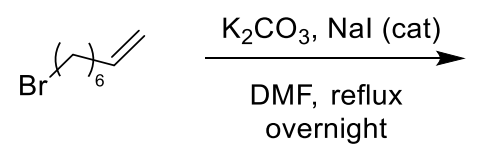<smiles>C=COc1ccc2c(c1)C(=O)c1ccc(OC(C)C)cc1C2=O</smiles>

Figures 1: Synthesis reaction scheme of mac-AQ.

Anthraflavic Acid (0.5 g, $2.08 \mathrm{mmol}, 1 \mathrm{eq})$ was dispersed with sonication in dry dimethylformamide (DMF) (21 mL, 0.1 M). Then, dry carbonate potassium $\left(\mathrm{K}_{2} \mathrm{CO}_{3}\right)(0.86 \mathrm{~g}, 6.24 \mathrm{mmol}, 3 \mathrm{eq})$, 8-Bromo1-octene $(0.7 \mathrm{~mL}, 4.16 \mathrm{mmol}, 2 \mathrm{eq})$ and catalytic amount of sodium iodide (NaI) were added and the mixture was refluxed overnight under $\mathrm{N}_{2}$ atmosphere. The next day, the crude of the reaction was allowed to $\mathrm{rt}$ and was poured into ice-cold $1 \mathrm{M} \mathrm{HCl}$ and the precipitate was filtered. The solid was redissolved in dicloromethane (DCM) and washed with water twice times. The organic phase was dried over $\mathrm{Na}_{2} \mathrm{SO}_{4}$ and the solvent was evaporated under reduced pressure. Finally, the crude was purified by flash chromatography (DCM) to obtain the product in $86 \%$ yield. ${ }^{1} \mathrm{H} \mathrm{NMR} \mathrm{(400} \mathrm{MHz,}$ $\left.\mathrm{CDCl}_{3}\right) \delta 8.22(\mathrm{~d}, J=8.7 \mathrm{~Hz}, 2 \mathrm{H}), 7.70(\mathrm{~d}, J=2.6 \mathrm{~Hz}, 2 \mathrm{H}), 7.21(\mathrm{dd}, J=8.7,2.7 \mathrm{~Hz}, 2 \mathrm{H}), 5.82(\mathrm{ddt}$, $J=16.9,10.2,6.7 \mathrm{~Hz}, 2 \mathrm{H}), 5.07-4.90(\mathrm{~m}, 4 \mathrm{H}), 4.14(\mathrm{t}, J=6.5 \mathrm{~Hz}, 4 \mathrm{H}), 2.07(\mathrm{q}, J=6.9 \mathrm{~Hz}, 4 \mathrm{H})$, 
$1.90-1.78(\mathrm{~m}, 4 \mathrm{H}), 1.55-1.32(\mathrm{~m}, 12 \mathrm{H}) .{ }^{13} \mathrm{C} \mathrm{NMR}\left(101 \mathrm{MHz}, \mathrm{CDCl}_{3}\right) \delta 182.5,164.2,139.1,136.0$, 129.8, 127.1, 121.1, 114.5, 110.7, 68.9, 33.8, 29.1, 28.9, 26.0. MALDI calculated for $\mathrm{C}_{30} \mathrm{H}_{36} \mathrm{NaO}_{4}$ [M+Na]+ : 483.2506; found 483.2522.

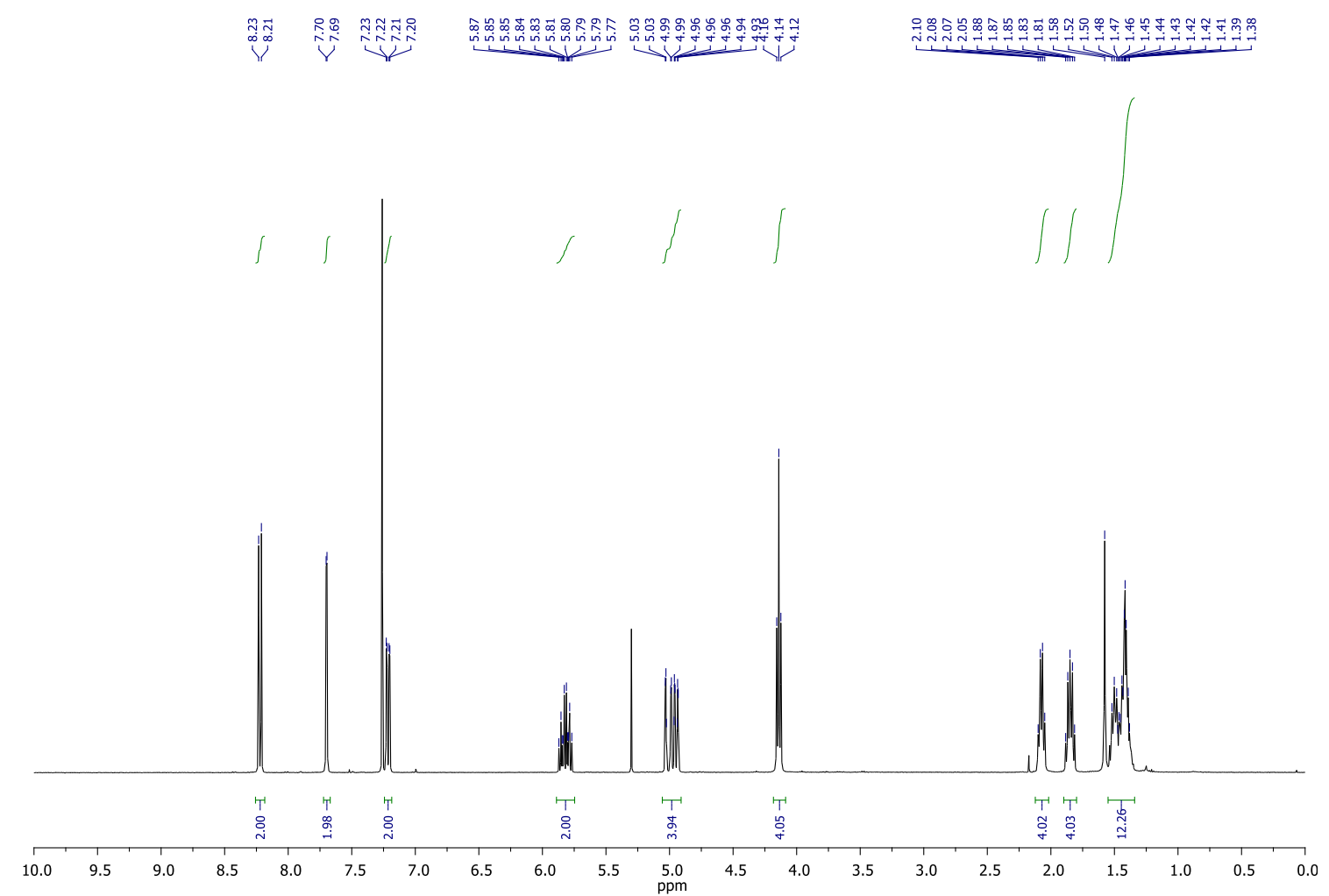

FigureS 2: ${ }^{1} \mathrm{H}-\mathrm{NMR}$ spectrum of $\boldsymbol{C}_{8}-\mathrm{AQ}-\mathrm{C}_{8}\left(\mathrm{CDCl}_{3}, 298 \mathrm{~K}\right)$. 

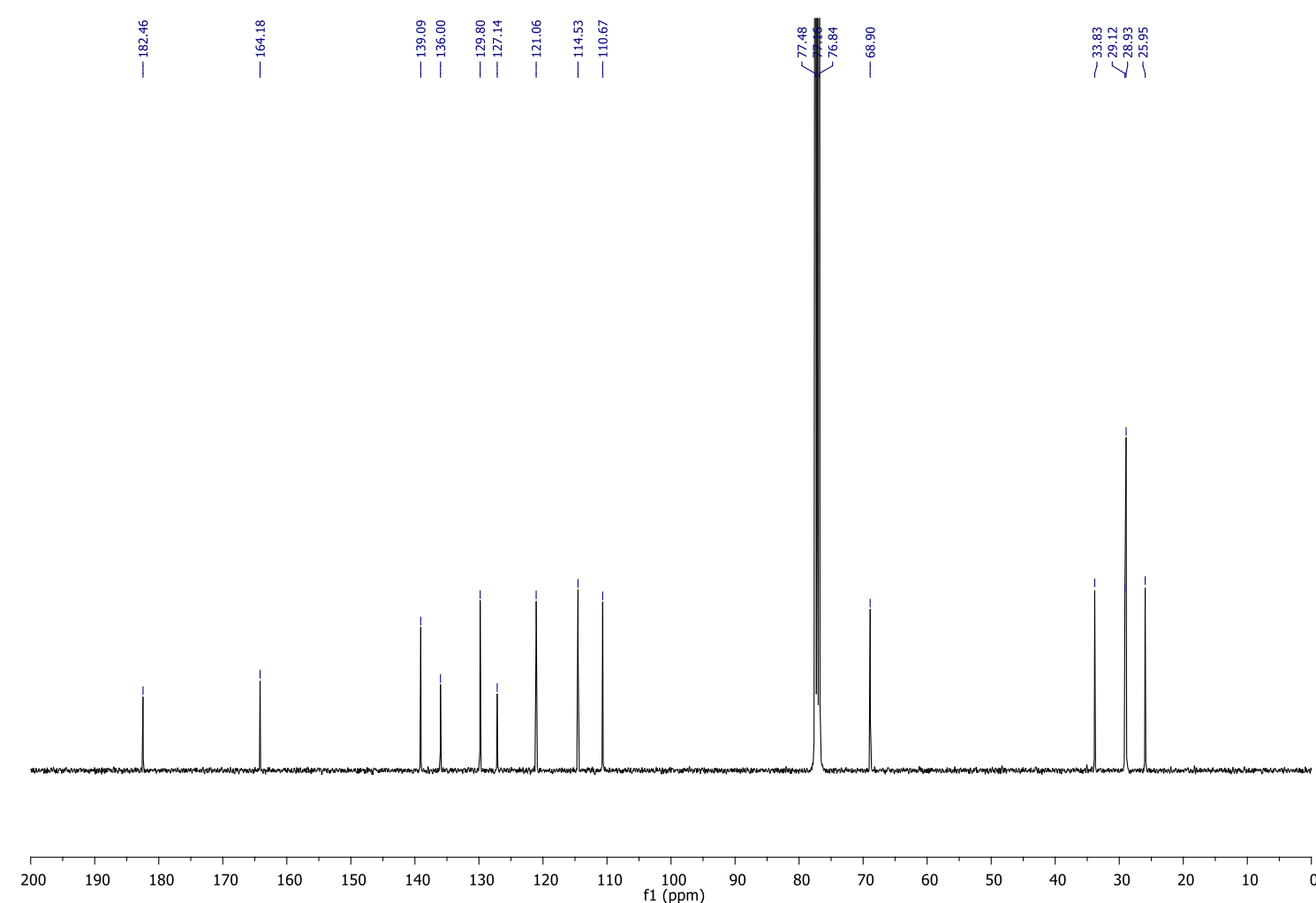

FigureS 3: ${ }^{13} \mathrm{C}-\mathrm{NMR}$ spectrum of $\boldsymbol{C}_{8}-\boldsymbol{A} \boldsymbol{Q}-\boldsymbol{C}_{8}\left(\mathrm{CDCl}_{3}, 298 \mathrm{~K}\right)$.

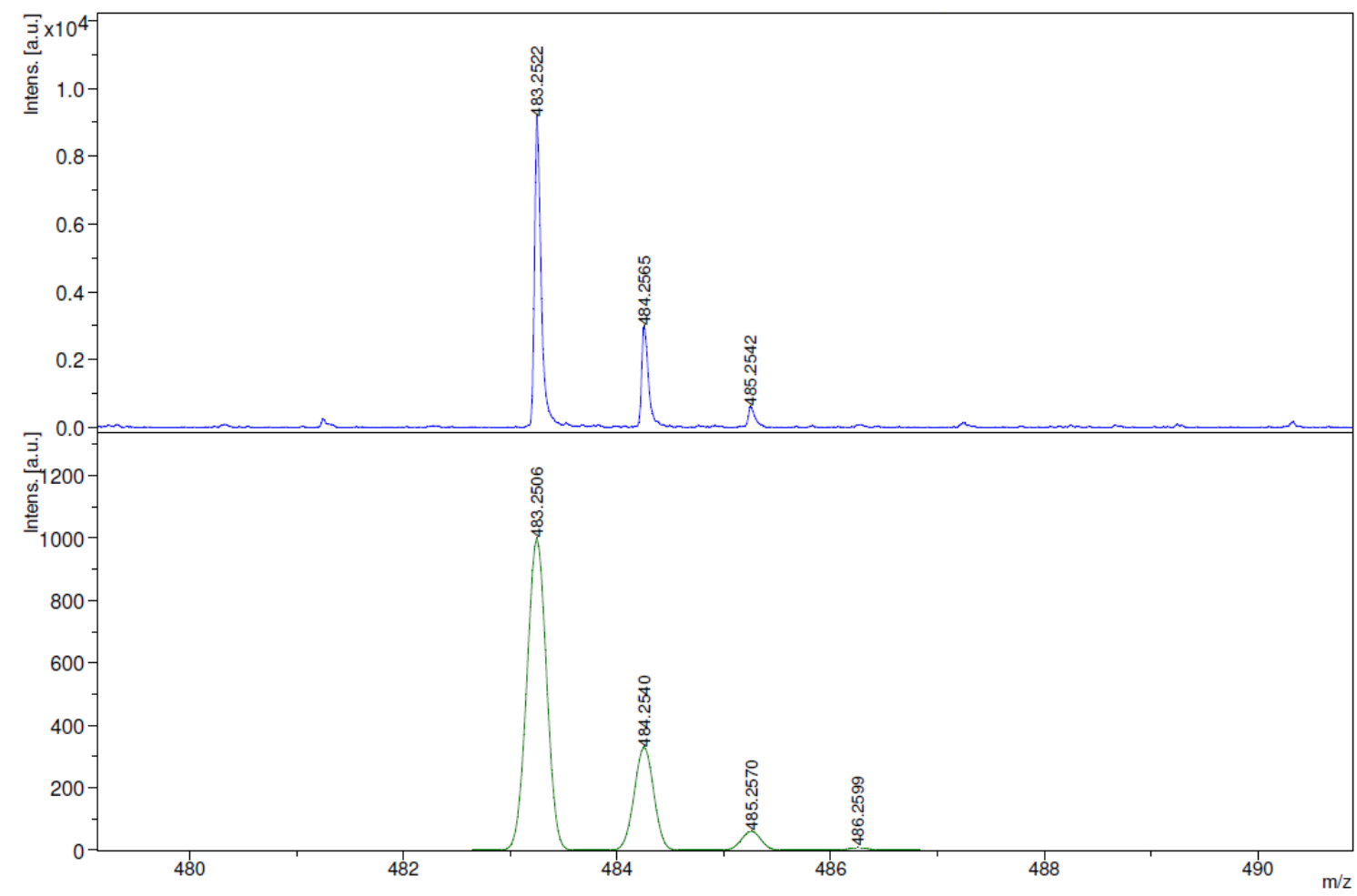

FigureS 4: MALDI spectra of $C_{8}-A Q-C 8$. 


\section{Synthesis and characterization of MINT}

The (6,5)- enriched SWCNTs purchased from Sigma Aldrich were purified previously. $100 \mathrm{mg}$ of SWCNTs were suspended in $70 \mathrm{~mL}$ of $35 \% \mathrm{HCl}$, and sonicated for $10 \mathrm{~min}$. The mixture was poured in $200 \mathrm{~mL}$ of MQ water and filtered through a polycarbonate membrane of $0.2 \mu \mathrm{m}$ pore size. The solid was washed with water to neutral $\mathrm{pH}$ and then dried in an oven at $350{ }^{\circ} \mathrm{C}$ for $30 \mathrm{~min}$. Pristine plasma-purified SWCNTs were used without previous purification.

The pristine $(10 \mathrm{mg})$ were suspended in $10 \mathrm{~mL}$ of tetrachloroethane through sonication (10 $\mathrm{min})$ and mixed with $0.01 \mathrm{mmol}$ of linear bisalkene U-shaped mac-AQ $\mathbf{Q}^{3}$, and Grubbs' second-generation catalyst at room temperature for $72 \mathrm{~h}$ under $\mathrm{N}_{2}$ atmosphere. After this time, the suspension was filtered through a PTFE membrane of $0.2 \mu \mathrm{m}$ pore size and the solid washed profusely with DCM. The solid was re-suspended in $10 \mathrm{~mL}$ of DCM through sonication for $10 \mathrm{~min}$ and filtered through a PTFE membrane of $0.2 \mu \mathrm{m} 4$ pore size again. This washing procedure was repeated three times. The sample obtained was denoted as AQ-MINT ${ }^{4}$. The synthesis of the supramolecular complex was denoted as AQ@SW-CNT and was performed by the direct mixing of the adequate amounts of 6,5-SW-CNT and the corresponding macrocycle without catalyst to achieve the same functionalization loading of organic material over the nanotube compared to their respective MINT sample. Two samples with different loading of the macrocycle have been synthesized.

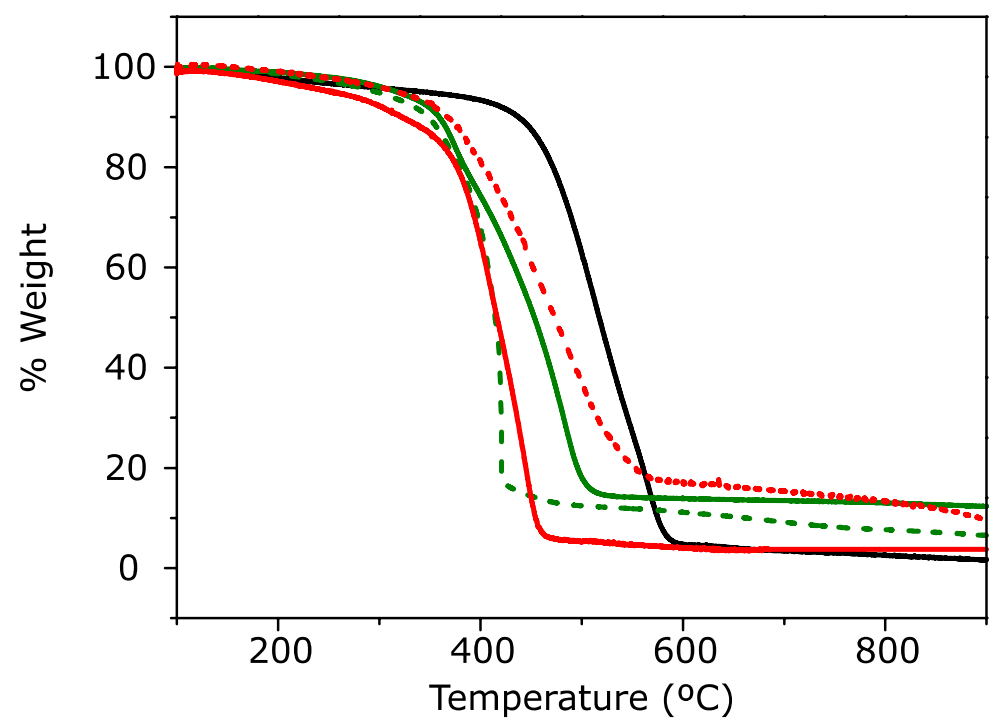

FigureS 5: TGA plots (ramp of $10{ }^{\circ} \mathrm{C} \mathrm{min} \mathrm{min}^{-1}$ under air from 100 to $900{ }^{\circ} \mathrm{C}$ ) of SW-CNT (black), AQ-MINT (green), AQ@SW-CNT (red), AQ-MINT with low loading (green dashed line) and AQ@SW-CNT with low loading (red dashed line). 


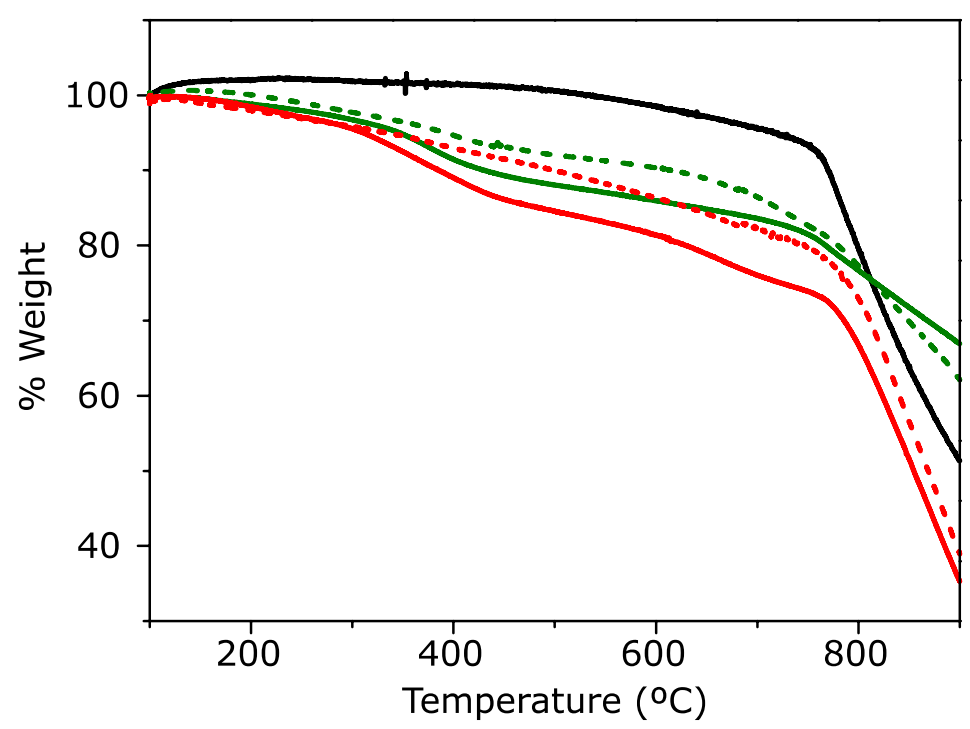

FigureS 6: TGA plots (ramp of $10^{\circ} \mathrm{C} \mathrm{min}^{-1}$ under $\mathrm{N}_{2}$ from 100 to $900{ }^{\circ} \mathrm{C}$ ) of $\mathrm{SW}$-CNT (black), AQ-MINT (green), AQ@ $\mathrm{SW}$-CNT (red), AQ-MINT with low loading (green dashed line) and AQ@SWCNT with low loading (red dashed line).

\section{Determination of hydrogen hydroxide $\left(\mathrm{H}_{2} \mathrm{O}_{2}\right)$ production}

The detection of $\mathrm{H}_{2} \mathrm{O}_{2}$ was done accordingly to recent literature reports ${ }^{1,2}$. Mixtures in a 1:1 ratio of $4 \mathrm{mM}$ p-nitrophenyl boronic acid ( $p$ NBA, Sigma Aldrich, >95\%) in DMSO (VWR) and a $150 \mathrm{mM}$ $\mathrm{Na}_{2} \mathrm{CO}_{3} / \mathrm{NaHCO}_{3}$ (Fluka, >99.5\%; Sigma Aldrich, 99.7-100.3\%)) buffer solution pH 9 were mixed with the sample. After 36 min incubation at room temperature under dark condition, the absorbance at $411 \mathrm{~nm}$ was recorded using a Thermo Fischer Multiskan Go Microplate Spectrophotometer. The amount of $\mathrm{H}_{2} \mathrm{O}_{2}$ was determined using a calibration curve made from $\mathrm{H}_{2} \mathrm{O}_{2}$ standard solution (Merck, 30\%) (Figure S7). The measured absorbance was subtracted with the absorbance of blank sample (incubation of deionized water with chromophore). The subtracted value, $\Delta$ absorbance, was used for the quantification.
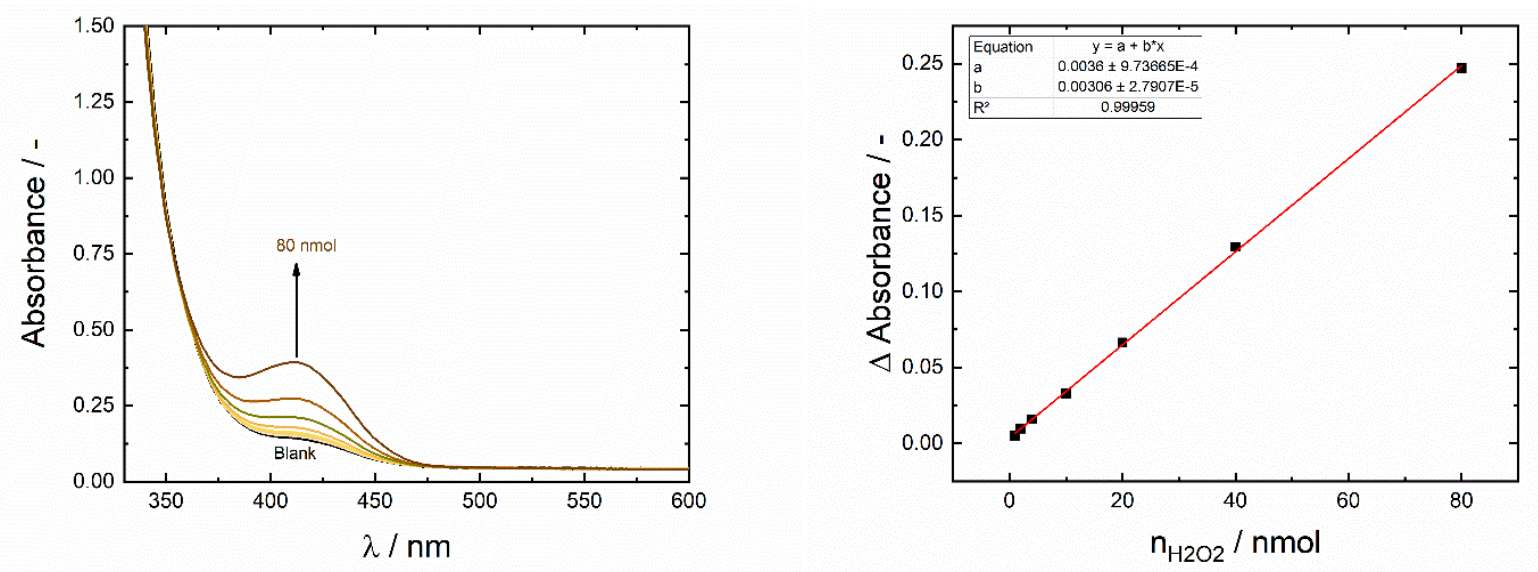

Figure S7: a) Absorption spectra of standard $\mathrm{H}_{2} \mathrm{O}_{2}$ solution at various concentrations and b) calibration curves of the $\mathrm{H}_{2} \mathrm{O}_{2}$ quantification including the formula. 


\section{Spectroscopical characterization of MINT}

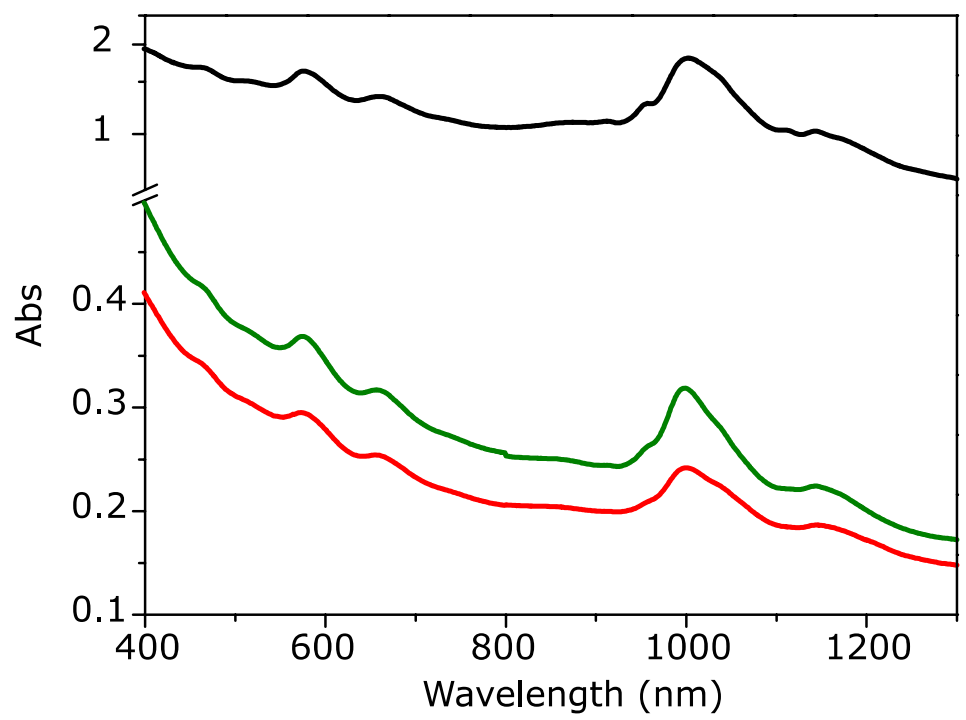

FigureS 8: UV-Vis spectra ( $\mathrm{D}_{2} \mathrm{O} / \mathrm{SDS}(1$ wt. \%) at room temperature) of SW-CNT (black), AQ-MINT (green) and AQ@SW-CNT (red).

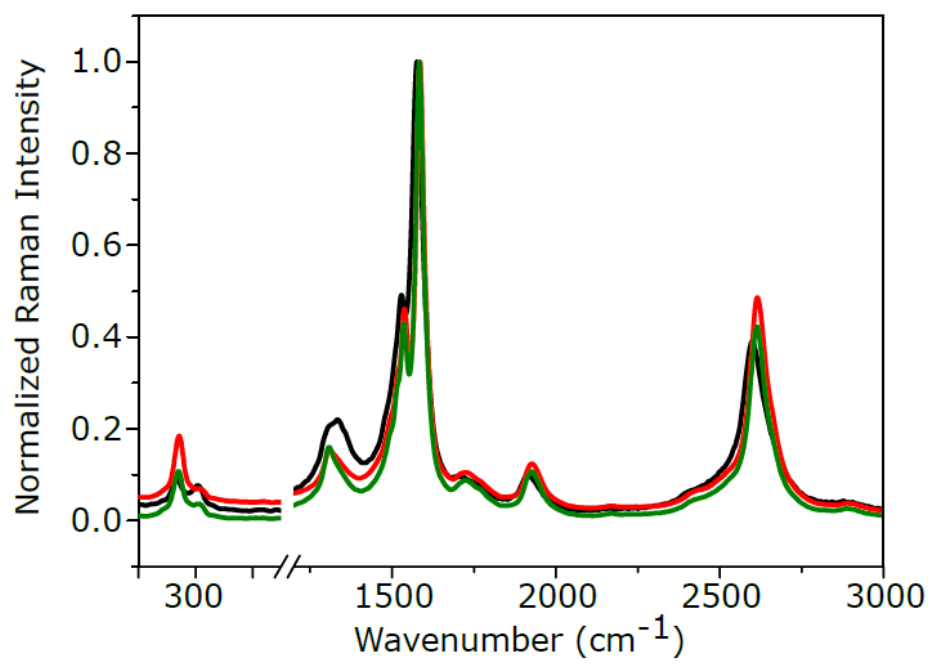

FigureS 9: Raman spectroscopy. Average $(N=25)$. Raman spectra of SWNT (black), AQ-MINT (green) and AQ@SWCNT (red). 

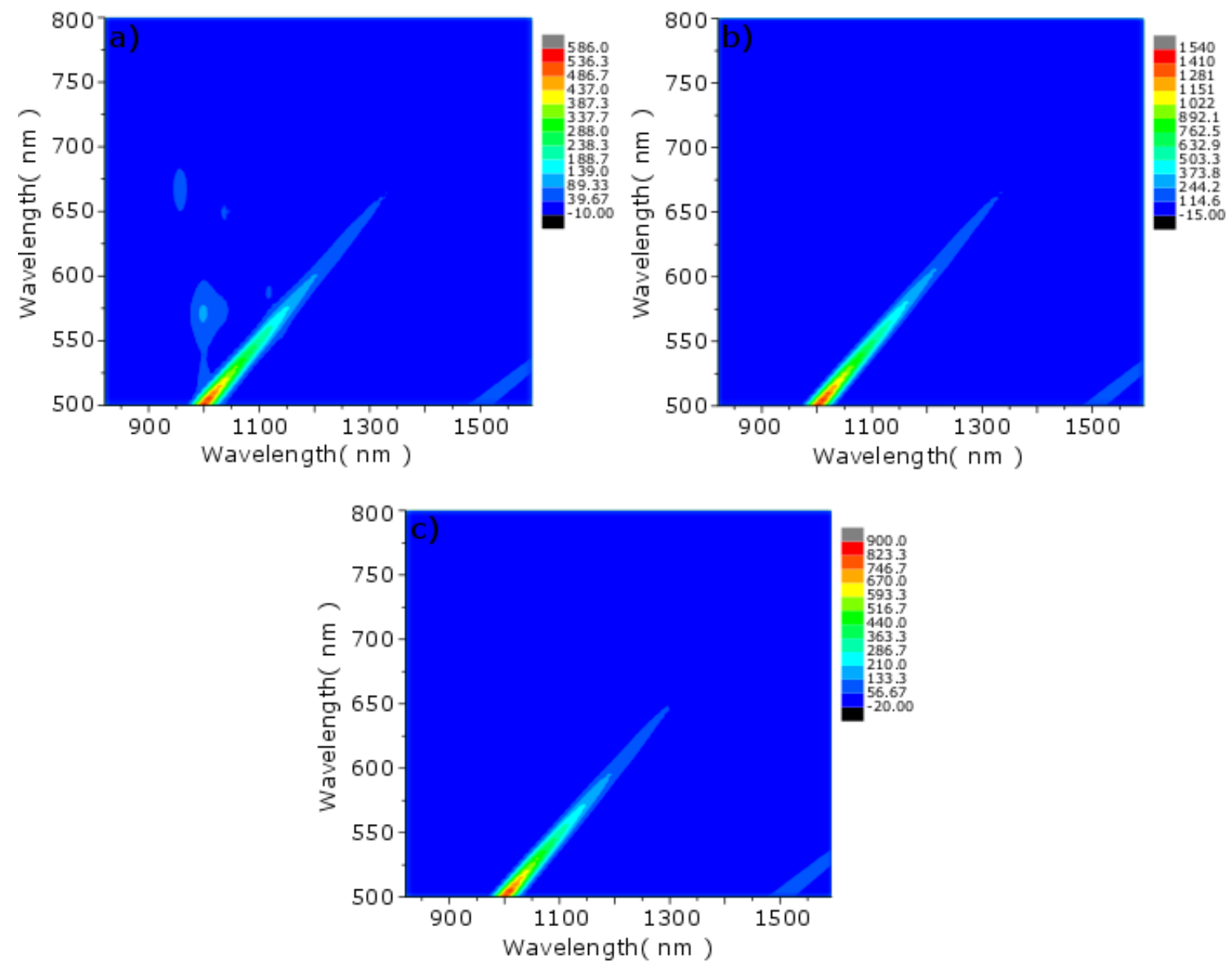

FigureS 10: PLE map of a) (6,5)-SWNT, b) AQ-MINT and c) AQ@SWCNT. 


\section{Homogeneous CV investigations}

As mentioned in the article, an octyloxy-AQ derivative was chosen to compare it to the AQ-MINT electrochemical experiments. In the following Figure S11 the CV of $2.5 \mathrm{mM}$ AQ is compared with the $\mathrm{CV}$ of $1 \mathrm{mM}$ octyloxy-AQ in $0.1 \mathrm{M} \mathrm{TBAPF}_{6}$ in $\mathrm{MeCN}$ solution.
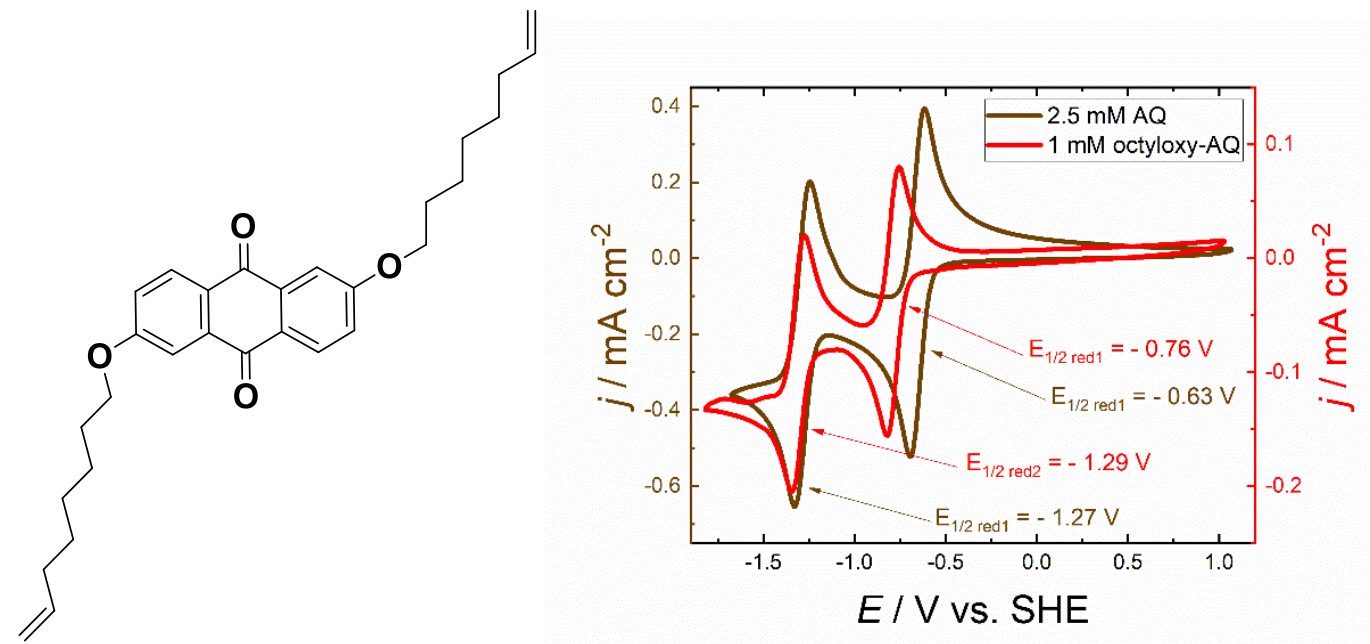

Figure S11: a)Structure of the (bis)octyloxy-AQ and b) cyclic voltammograms of 2.5mM AQ and $1 \mathrm{mM}$ octyloxy-AQ recorded in MeCN containing $0.1 \mathrm{M} \mathrm{TBAPF}_{6}$ with scan rates of $20 \mathrm{mV} \mathrm{s}^{-1}$.

The CV curves shown in Figure S11 show, that the alkoxy substituents shift the first reduction wave cathodically by $130 \mathrm{mV}$ whereas the second reduction wave is nearly unaffected.

\section{CV study of SW-CNT}

Complementary to Figure $2 \mathrm{a}$ and $4 \mathrm{a}$ in the main text, the following FigureS 12 shows a the $\mathrm{CV}$ curve of SW-CNT sample in $0.1 \mathrm{M} \mathrm{Na} \mathrm{SO}_{4}$ under $\mathrm{N}_{2}$ and $\mathrm{O}_{2}$ :

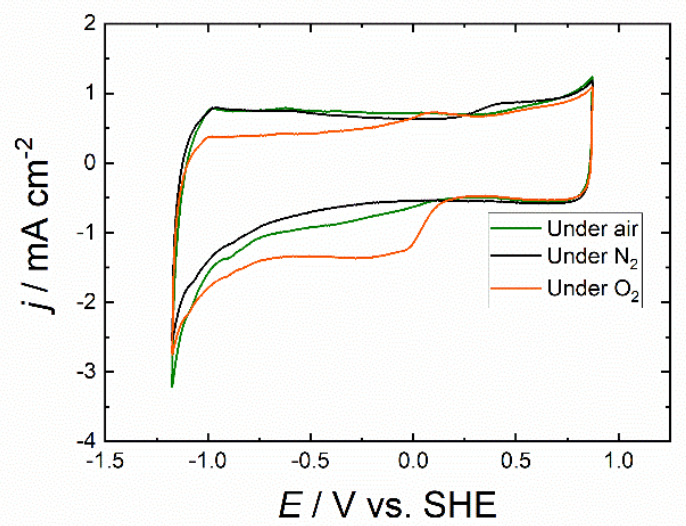

Figures 12: Cyclic voltammograms of SWCNT in $0.1 \mathrm{M} \mathrm{Na}_{2} \mathrm{SO}_{4}$ aqueous solution under $\mathrm{N}_{2}$ - and $\mathrm{O}_{2}$-saturated conditions.

As can be seen from FigureS 12, also pristine SWCNT show a reductive step upon $\mathrm{O}_{2}$ addition, which is already a hint for oxygen reduction 


\section{Cycle stability - non-aqueous conditions}

In the following Figure S13, the cycle stability of AQ-MINT in the organic conditions of $0.1 \mathrm{M}$ $\mathrm{TBAPF}_{6}$ in $\mathrm{MeCN}$ is shown.

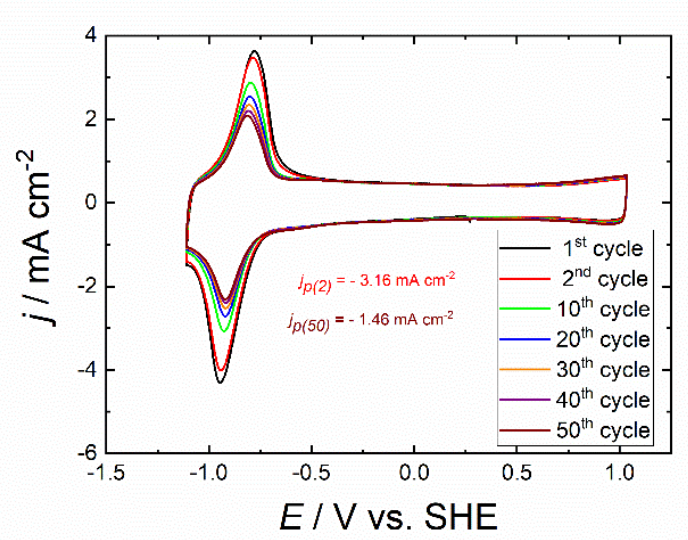

Figure S13: CV curve of AQ-MINT in MeCN containing 0.1 M TBAPF6 upon 50 sweeping cycles.

In general, a similar behaviour like in aqueous solution (see Figure 3) was observed. The lower $j_{P}$ can be explained by the fact that, in organic solvents in this potential range only a 1-electron reduction process is taking place.

\section{Kinetic investigations}

Regarding the cycle stability test, AQ-MINT was reasonably stable, while AQ@SWCNT suffered from severe loss of $j_{P}$ over 50 cycles. Nevertheless, kinetic studies of both AQ-MINT and AQ@SWCNT were performed by CV with varied scan rate (Figure 3a and b). Due to the fact that especially the AQ@SWCNT sample with the 15\% loading (and also the AQ-MINT sample with 13\%) suffered from significant loss of $j_{P}$ during the kinetic studies, from continuous delamination over the experiment time, no further kinetic data could be extracted thereof. The investigation of samples with lower loadings proved sufficient stability, therefore the mentioned kinetic studies and analysis could be determined.

In the following Figure S14 all the CV's of AQ-MINT $(4 \% \mathrm{~m} / \mathrm{m})$ as well as AQ@SWCNT $(6 \% \mathrm{~m} / \mathrm{m})$ on $\mathrm{GC}$ electrodes in $0.1 \mathrm{M} \mathrm{Na}_{2} \mathrm{SO}_{4}$ in $\mathrm{H}_{2} \mathrm{O}$ are shown. 


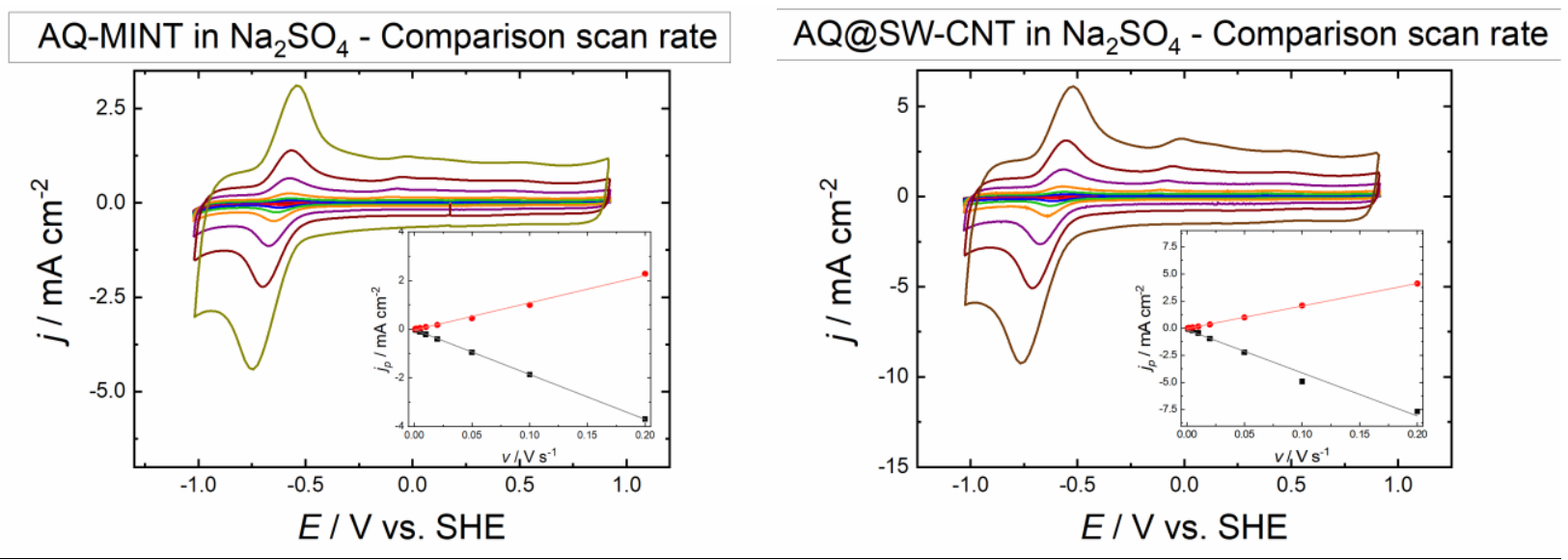

Figure S14: Cyclic voltammograms of a) AQ-MINT and b) AQ@SWCNT recorded in $0.1 \mathrm{M} \mathrm{Na}_{2} \mathrm{SO}_{4}$ aqueous solution with various scan rates of $1,2,5,10,20,50,100$ and $200 \mathrm{mV} \mathrm{s}^{-1}$. The insets show plots of $j_{p}$ vs the scan rate.

The curves shown in Figure S14 were analysed concerning peak currents $j_{P}$ 's and the resulting plots as are shown as insets. In both cases, a linear correlation of the jp with the scan rate $(v)$ was observed. Also, the integrated peak charges were calculated where in case of both AQ-MINT batches quite stable values of, in case of both AQ@SWCNT due to degradation over the cycles only decreasing values were observed.

\section{Further investigations on $\mathrm{O}_{2}$ reduction with AQ-MINT and SWCNT}

In order to prove, that the AQ-MINT is stable on the electrode over the time of the electrolysis, in the following Figure S15, CV curves before and after were compared:

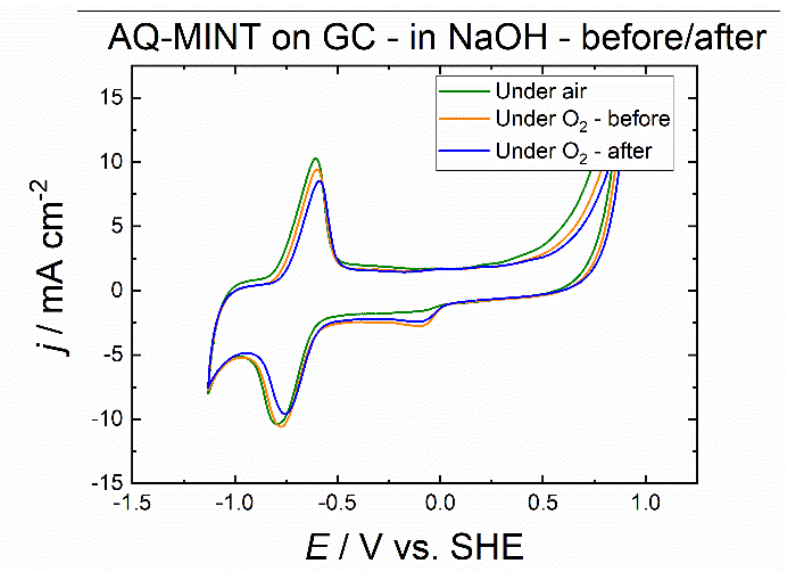

Figure S15: Cyclic voltammograms of AQ-MINT recorded in $0.1 \mathrm{M} \mathrm{NaOH}$ under air and $\mathrm{O}_{2}$-saturated conditions before and after 8-h electrolysis.

From the CV in Figure S15 it can be stated, that the AQ-MINT is very stable under the conditions of electrolysis and shows just a slight decrease in $j_{P}$ of $6.3 \%$.

All details on the kinetic parameters like the total moles of $\mathrm{H}_{2} \mathrm{O}_{2}$ produced, the rate and the Faradaic efficiency (FE) of oxygen reduction electrolysis at different conditions are displayed in the following Table S1: 


\section{SWCNT}

\begin{tabular}{|c|c|c|c|c|c|c|}
\hline \multirow{3}{*}{$\begin{array}{l}\text { Time } \\
\text { / h }\end{array}$} & \multicolumn{3}{|c|}{ In $0.1 \mathrm{M} \mathrm{Na}_{2} \mathrm{SO}_{4}$} & \multicolumn{3}{|c|}{ In $0.1 \mathrm{M} \mathrm{NaOH}$} \\
\hline & $\mathrm{n}_{(\mathrm{H} 2 \mathrm{O} 2)^{[\mathrm{a}]}}$ & $\mathrm{H}_{2} \mathrm{O}_{2}$ production rate ${ }^{[b]}$ & $\mathrm{FE}^{[\mathrm{b}]}$ & $\mathrm{n}_{(\mathrm{H} 2 \mathrm{O} 2)}{ }^{[\mathrm{a}]}$ & $\mathrm{H}_{2} \mathrm{O}_{2}$ production rate ${ }^{[b]}$ & $\mathrm{FE}^{[\mathrm{b}]}$ \\
\hline & $/ \mu \mathrm{mol}$ & $/ \mu$ mol $_{\mathrm{H} 2 \mathrm{O} 2} \mathrm{mg}^{-1} \mathrm{~h}^{-1}$ & $1 \%$ & / $\mu \mathrm{mol}$ & $/ \mu$ mol $_{\mathrm{H} 2 \mathrm{O} 2} \mathrm{mg}^{-1} \mathrm{~h}^{-11}$ & $1 \%$ \\
\hline Initial & 0.94 & n. d. & n. d. & 0.16 & n. d. & n. d. \\
\hline 1 & 0.85 & n. d. & n. d. & 0.29 & 1.28 & 14.7 \\
\hline 2 & 0.80 & n. d. & n. d. & 0.60 & 3.19 & 43.0 \\
\hline 4 & 1.09 & 1.46 & 17.4 & 1.09 & 2.42 & 36.0 \\
\hline 6 & 1.35 & 1.33 & 19.9 & 1.97 & 4.39 & 78.6 \\
\hline 8 & 1.41 & 0.26 & 4.7 & 2.37 & 2.02 & 43.7 \\
\hline \multicolumn{7}{|c|}{ AQ-MINT } \\
\hline
\end{tabular}

\begin{tabular}{|c|c|c|c|c|c|c|}
\hline \multirow{3}{*}{$\begin{array}{l}\text { Time } \\
\text { / h }\end{array}$} & \multicolumn{3}{|c|}{ In $0.1 \mathrm{M} \mathrm{Na}_{2} \mathrm{SO}_{4}$} & \multicolumn{3}{|c|}{ In $0.1 \mathrm{M} \mathrm{NaOH}$} \\
\hline & $\mathrm{n}\left(\mathrm{H}_{2} \mathrm{O}_{2}\right)^{[\mathrm{a}]}$ & $\mathrm{H}_{2} \mathrm{O}_{2}$ production rate $\mathrm{e}^{[\mathrm{b}]}$ & $\mathrm{FE}^{[\mathrm{b}]}$ & $\mathrm{n}\left(\mathrm{H}_{2} \mathrm{O}_{2}\right)^{[\mathrm{a}]}$ & $\mathrm{H}_{2} \mathrm{O}_{2}$ production rate ${ }^{[\mathrm{b}]}$ & $\mathrm{FE}^{[\mathrm{b}]}$ \\
\hline & $/ \mu \mathrm{mol}$ & $/ \mu \mathrm{mol}_{\mathrm{H} 2 \mathrm{O} 2} \mathrm{mg}^{-1} \mathrm{~h}^{-1}$ & $1 \%$ & $/ \mu \mathrm{mol}$ & $/ \mu \mathrm{mol}_{\mathrm{H} 2 \mathrm{O} 2} \mathrm{mg}^{-1} \mathrm{~h}^{-1}$ & $1 \%$ \\
\hline Initial & 0.20 & n. d. & n. d. & 0.46 & n. d. & n. d. \\
\hline 1 & 0.29 & 0.86 & 2.5 & 1.69 & 12.31 & 50.7 \\
\hline 2 & 0.48 & 1.91 & 5.4 & 2.85 & 11.66 & 51.6 \\
\hline 4 & 1.24 & 3.81 & 11.2 & 4.34 & 7.44 & 34.8 \\
\hline 6 & 1.50 & 1.32 & 3.8 & 6.02 & 8.38 & 41.5 \\
\hline 8 & 2.14 & $\mathrm{AQ}$ & $\begin{array}{r}9.6 \\
\mathbf{W C l}\end{array}$ & 7.46 & 7.20 & 36.7 \\
\hline
\end{tabular}

\begin{tabular}{|c|c|c|c|c|c|c|}
\hline \multirow{3}{*}{$\begin{array}{l}\text { Time } \\
\text { / h }\end{array}$} & \multicolumn{3}{|c|}{ In $0.1 \mathrm{M} \mathrm{Na}_{2} \mathrm{SO}_{4}$} & \multicolumn{3}{|c|}{ In $0.1 \mathrm{M} \mathrm{NaOH}$} \\
\hline & $\mathrm{n}\left(\mathrm{H}_{2} \mathrm{O}_{2}\right)^{[\mathrm{a}]}$ & $\mathrm{H}_{2} \mathrm{O}_{2}$ production rate ${ }^{[b]}$ & $\mathrm{FE}^{[\mathrm{b}]}$ & $\mathrm{n}\left(\mathrm{H}_{2} \mathrm{O}_{2}\right)^{[\mathrm{a}]}$ & $\mathrm{H}_{2} \mathrm{O}_{2}$ production rate ${ }^{[b]}$ & $\mathrm{FE}^{[\mathrm{b}]}$ \\
\hline & $/ \mu \mathrm{mol}$ & $/ \mu \mathrm{mol}_{\mathrm{H} 2 \mathrm{O} 2} \mathrm{mg}^{-1} \mathrm{~h}^{-1}$ & $1 \%$ & $/ \mu \mathrm{mol}$ & $/ \mu \mathrm{mol}_{\mathrm{H} 2 \mathrm{O} 2} \mathrm{mg}^{-1} \mathrm{~h}^{-11}$ & $1 \%$ \\
\hline Initial & 0.39 & n. d. & n. d. & 1.54 & n. d. & n. d. \\
\hline 1 & 0.48 & 0.86 & 4.4 & 2.06 & 5.18 & 14.6 \\
\hline 2 & 0.67 & 1.89 & 10.8 & 2.47 & 4.13 & 17.2 \\
\hline 4 & 0.98 & 1.57 & 8.1 & 3.36 & 4.48 & 27.4 \\
\hline 0 & 1.38 & 1.97 & 10.1 & 4.41 & 5.25 & 47.5 \\
\hline 0 & 1.80 & 2.15 & 11.7 & 5.95 & 7.68 & 84.6 \\
\hline
\end{tabular}

[a] Cumulative, absolute amount of $\mathrm{H}_{2} \mathrm{O}_{2}$ detected by spectrophotometer.

[b] Calculated per time interval 


\section{RDE Experiments}

Samples of SW-CNT, AQ-MINT and AQ@SWCNT were drop-casted onto RDE electrodes with the same loading and tested under $\mathrm{O}_{2}$ saturation in $0.1 \mathrm{M} \mathrm{NaOH}$ solution. The rotation speed was varied between 100 and $3600 \mathrm{rpm}$. In order to show ORR, linear sweep voltammograms $(L S V)$ of an intermediate and representative speed of $1200 \mathrm{rpm}$ was chosen to compare the three samples in Figure 4c.

Comparing the current densities of the three samples revealed that AQ-MINT shows the highest catalytic current. Nevertheless, performing Koutecki-Levich-Analysis ${ }^{5}$ using eq. 1 showed that assuming the geometric electrode surface area is significantly underestimating the real electrode surface area with the CNT structure.

$$
\frac{1}{i}=\frac{1}{i_{K}}+\frac{1}{0.62 n F A D^{2 / 3} v^{-1 / 6} c_{0}} \cdot \frac{1}{\omega^{1 / 2}}
$$

Although the lack of the exact electrode area hinders further analysis of the slope in Koutecki-LevichPlot, still the values of $i_{K}$ correlate with the rate constant $\mathrm{k}$, as shown in eq. 2 :

$$
i_{K}=n F A k_{f}(E) c_{0}
$$

As those values of $i_{K}$ refer to the exchange current without any convection effects, it can still be regarded as value for comparing the three systems as they arrange on the electrode surface.
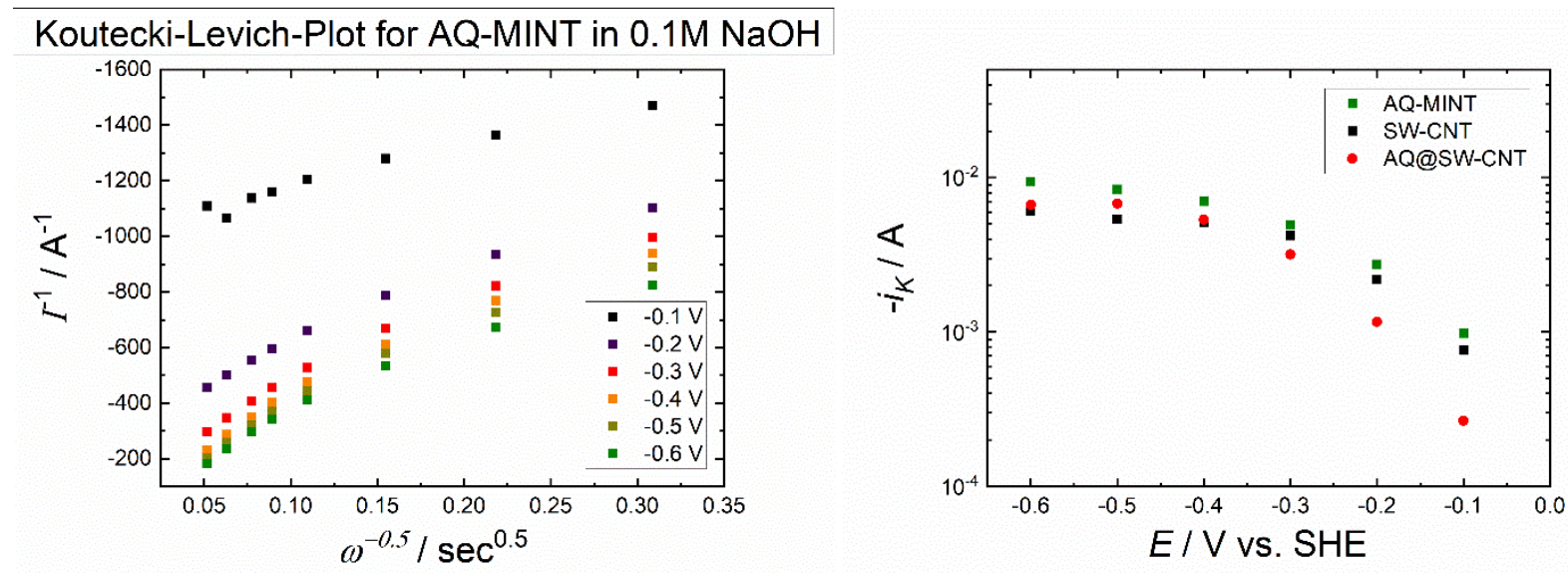

FigureS 16: a) Koutecki-Levich plots of AQ-MINT in $0.1 \mathrm{M} \mathrm{NaOH}$ at potentials between -0.1 and -0.6V. b) $i_{K}$ values of AQ-MINT, $A Q @ S W-C N T$ and SW-CNT determined from the intercept of the Koutecki-Levich plots depending on the potential applied.

As can be seen from FigureS 16a, the Koutecki-Levich plots for AQ-MINT show a reasonable linear trend for those potentials applied. Plotting the $i_{K}$ values of AQ-MINT, AQ@SWCNT and SWCNT from the Koutecki-Levich plots show that at more positive potentials AQ@SWCNT and SWCNT 
differ but come to quite close values at more negative potentials. In all potentials regarded, AQ-MINT shows the highest $i_{K}$ which can be regarded as a hint for a higher electrocatalytic activity.

As a result, we propose that the different CNT samples with and without AQ modification arrange in a different way on the GC surface, which also affects the real, electroactive surface area. Unfortunately, because of insufficient resolution of the SEM facilities available, we were not able to proof this assumption.

\section{References:}

(1) Su, G.; Wei, Y.; Guo, M. Direct Colorimetric Detection of Hydrogen Peroxide Using 4Nitrophenyl Boronic Acid or Its Pinacol Ester. Am. J. Anal. Chem. 2011, 2, 879-884. https://doi.org/10.4236/ajac.2011.28101.

(2) Apaydin, D. H.; Seelajaroen, H.; Pengsakul, O.; Thamyongkit, P.; Sariciftci, N. S.; KunzeLiebhäuser, J.; Portenkirchner, E. Photoelectrocatalytic Synthesis of Hydrogen Peroxide by Molecular Copper-Porphyrin Supported on Titanium Dioxide Nanotubes. ChemCatChem 2018, 10 (8), 1793-1797. https://doi.org/10.1002/cctc.201702055.

(3) Canevet, D.; Gallego, M.; Isla, H.; Juan, A. De; Emilio, M. P. Macrocyclic Hosts for Fullerenes : Extreme Changes in Binding Abilities with Small Structural Variations . J. Am. Chem. Soc. 2011, 133 (9), 3184-3190. https://doi.org/10.1021/ja111072j.

(4) Blanco, M.; Nieto-Ortega, B.; De Juan, A.; Vera-Hidalgo, M.; López-Moreno, A.; Casado, S.; González, L. R.; Sawada, H.; González-Calbet, J. M.; Pérez, E. M. Positive and Negative Regulation of Carbon Nanotube Catalysts through Encapsulation within Macrocycles. Nat. Commun. 2018, 9 (2671), 1-7. https://doi.org/10.1038/s41467-018-05183-8.

(5) Bard, A. J.; Faulkner, L. R. Electrochemical Methods, 2nd Ed.; John Wiley \& Sons, Inc.: New York, 2001. 